\title{
The Influence of Chronic Exposure to Antipsychotic Medications on Brain Size before and after Tissue Fixation: A Comparison of Haloperidol and Olanzapine in Macaque Monkeys
}

\author{
Karl-Anton Dorph-Petersen', Joseph N Pierri', James M Perel ${ }^{1,2}$, Zhuoxin Sun ${ }^{3}$, Allan R Sampson ${ }^{3}$ and \\ David A Lewis* $* 1,4$ \\ 'Department of Psychiatry, University of Pittsburgh, Pittsburgh, PA, USA; ${ }^{2}$ Department of Clinical Pharmacology, University of Pittsburgh, \\ Pittsburgh, PA, USA; ${ }^{3}$ Department of Statistics, University of Pittsburgh, Pittsburgh, PA, USA; ${ }^{4}$ Department of Neuroscience, University of \\ Pittsburgh, Pittsburgh, PA, USA
}

\begin{abstract}
It is unclear to what degree antipsychotic therapy confounds longitudinal imaging studies and post-mortem studies of subjects with schizophrenia. To investigate this problem, we developed a non-human primate model of chronic antipsychotic exposure. Three groups of six macaque monkeys each were exposed to oral haloperidol, olanzapine or sham for a 17-27 month period. The resulting plasma drug levels were comparable to those seen in subjects with schizophrenia treated with these medications. After the exposure, we observed an $8-11 \%$ reduction in mean fresh brain weights as well as left cerebrum fresh weights and volumes in both drug-treated groups compared to sham animals. The differences were observed across all major brain regions (frontal, parietal, temporal, occipital, and cerebellum), but appeared most robust in the frontal and parietal regions. Stereological analysis of the parietal region using Cavalieri's principle revealed similar volume reductions in both gray and white matter. In addition, we assessed the subsequent tissue shrinkage due to standard histological processing and found no evidence of differential shrinkage due to drug exposure. However, we observed a pronounced general shrinkage effect of $\sim 20 \%$ and a highly significant variation in shrinkage across brain regions. In conclusion, chronic exposure of non-human primates to antipsychotics was associated with reduced brain volume. Antipsychotic medication may confound post-mortem studies and longitudinal imaging studies of subjects with schizophrenia that depend upon volumetric measures.
\end{abstract} Neuropsychopharmacology (2005) 30, I649-166I. doi:I0.1038/sj.npp. I3007I0; published online 9 March 2005

Keywords: macaque monkeys; haloperidol; olanzapine; schizophrenia; shrinkage; stereology

\section{INTRODUCTION}

Investigations of the structure of the human brain, both via in vivo imaging (Shenton et al, 2001; Niznikiewicz et al, 2003) and post-mortem studies (Harrison, 1999; Harrison and Lewis, 2003), are essential for understanding the neurobiology of schizophrenia. However, use of antipsychotic medications as treatment for schizophrenia represents a potential confounding factor in many of these studies. For example, MRI studies of structural brain changes across time are limited by the fact that-due to

\footnotetext{
*Correspondence: Dr DA Lewis, Department of Psychiatry, University of Pittsburgh, 381। O'Hara Street, WI65। BST, Pittsburgh, PA I5213, USA, Tel: + I 412624 3934, Fax: + I 4126249910 ,

E-mail: lewisda@msx.upmc.edu

Received 13 September 2004; revised II January 2005; accepted I8 January 2005

Online publication: 31 January 2005 at http://www.acnp.org/citations/ NPPO 13 I 0504422/default.pdf
}

obvious ethical reasons - neither untreated subjects with schizophrenia nor control subjects exposed to antipsychotic medications can be used as comparison groups. Similarly, in post-mortem studies almost all subjects with schizophrenia have been treated with antipsychotic medications, whereas normal comparison subjects were not exposed to such medications.

We have advocated a three-fold strategy to address the problem of confounding due to chronic antipsychotic drug treatment in post-mortem studies of schizophrenia (Lewis, 2002). This strategy includes (1) the comparison of subjects with schizophrenia who were on or off medication at the time of death, (2) the comparison of subjects with other psychiatric disorders (eg major depression with psychosis) who were on or off antipsychotic medication at the time of death, and (3) the use of non-human primates exposed chronically to antipsychotic medications in a manner that mimics clinical practice. Although each of these approaches has its own intrinsic limitations, a convergence of findings 
across studies provides compelling evidence that antipsychotics do or do not account for the finding of interest. The third arm of this triad is particularly important because it is the only approach that permits fully controlled experimental conditions. In this regard, the non-human primate model may be informative not only for human post-mortem studies but also for interpreting the outcome of longitudinal in vivo imaging studies of subjects with schizophrenia. For example, such studies have found evidence of brain volume changes evolving with time (Thompson et al, 2001; Ho et al, 2003; Pantelis et al, 2003; Sporn et al, 2003) that are potentially related to disease progression, but that might also reflect an effect of treatment.

In addition to their effects on the brain in vivo (eg druginduced changes in cell number in a given brain region), antipsychotic drugs might also induce changes in brain structure or composition that affect post-mortem tissue behavior. For example, knowing whether antipsychotic drug exposure in vivo causes differential tissue shrinkage during histological processing is essential for interpreting postmortem volumetric studies.

Consequently, in this study, we developed a non-human primate model of oral antipsychotic treatment by chronically exposing groups of macaque monkeys to either haloperidol (a conventional antipsychotic), olanzapine (a second-generation antipsychotic) or sham (placebo). Using this model, we addressed the following questions: (1) Do antipsychotic medications induce changes in total or regional brain weight or volume? (2) Do antipsychotic medications affect the tissue shrinkage that occurs during post-mortem processing? (3) Do these effects differ as a function of type of antipsychotic drug?

\section{METHODS}

\section{Animals and Training}

Eighteen experimentally naïve male macaque monkeys (Macaca fascicularis), 4.5-5.3 years of age, were obtained from LABS of Virginia (Yemassee, SC). All animals were housed in single cages grouped together in the same room at the University of Pittsburgh Primate Research Laboratory. Six animals were randomly selected to form a group, with the remaining animals divided into two groups so that average body weights were approximately balanced across the three exposure groups (haloperidol, olanzapine, or sham). All studies were carried out in accordance with the NIH Guide for the Care and Use of Laboratory Animals and were approved by the University of Pittsburgh Institutional Animal Care and Use Committee.

All animals were trained to self-administer fruit punchflavored sucrose pellets. Self-administration of the pellets was reinforced with raisins and was followed by drinking $60 \mathrm{ml}$ of orange drink from a syringe. The orange drink was administrated in order to have an alternate vehicle for drug administration, should an animal become unreliable in ingesting the pellets. When animals achieved $100 \%$ compliance, sucrose pellets containing drug were introduced to the haloperidol group. Owing to delays in obtaining olanzapine, the animals in this group received sham pellets for the first $\sim 10$ months. Two monkeys initially allocated to the sham group were switched with two initially allocated to the olanzapine group immediately before the initiation of the olanzapine treatment (see Animal Health section below).

\section{Drug Preparation and Administration}

Sucrose pellets $(190 \mathrm{mg})$ containing haloperidol sulfate (Spectrum Chemicals and Laboratory Products, Gardena, CA), olanzapine (Eli Lilly, Indianapolis, IN), or no drug (sham pellets) were custom made (Research Diets Inc., New Brunswick, NJ). Two dosage levels per pellet were ordered for each drug. Quality control assays determined the content of haloperidol to be 1.0 or $2.0 \mathrm{mg} / \mathrm{pellet}$ and the content of olanzapine to be 0.55 or $1.1 \mathrm{mg} /$ pellet. Methods for quality control were identical to those used for drug plasma level analysis (see Blood Sampling section below).

All medication and sham treatments were administered orally twice daily (between 08:30 and 09:30, and between 15:30-16:30), 5 days a week for the first $\sim 5$ months and all 7 days a week for the rest of the study ( $\sim 22$ months). Each monkey could receive the drug in one of three ways: (1) by ingesting intact pellets; (2) by ingesting the dissolved drug (haloperidol) or pulverized pellets in orange drink; and (3) by ingesting pellets pulverized in treats consisting of fresh or dehydrated fruit, or mixed with peanut butter or jelly. All monkeys were always given orange drink containing quinine sulfate as a taste mask to prevent the animals from knowing whether or not drug was present. During the study, animals in the haloperidol and the olanzapine groups required increasingly greater effort to maintain compliance with the dosing regimen. The animals seemed to develop an aversion to the taste and/or the subjective effects of the medication. Thus, dosing vehicles were adapted to ensure that the animals complied with drug ingestion.

Drug doses were increased over time based upon the monitored drug plasma levels. The goal was to achieve and maintain plasma concentrations of each drug that approximated those associated with a therapeutic response in humans. In a previous study (Akil et al, 1999; Pierri et al, 1999), we exposed monkeys to doses of haloperidol decanoate, resulting in mean (SD) trough haloperidol plasma levels of $4.3 \pm 1.1 \mathrm{ng} / \mathrm{ml}$, which are similar to the mean (SD) plasma level of $4.9 \pm 2.9 \mathrm{ng} / \mathrm{ml}$ (total + reduced haloperidol) observed in humans treated according to the model of 'neuroleptic threshold dosing' (McEvoy et al, 1986, 1991). Consistent with this strategy, we observed notable extrapyramidal side effects in these animals. However, more recent imaging studies of dopamine $\mathrm{D}_{2}$ receptor occupancy suggest that antipsychotic efficacy, without pronounced extrapyramidal symptoms or hyperprolactinemia, occurs when $65-72 \%$ of striatal dopamine $\mathrm{D}_{2}$ receptor are occupied (Farde et al, 1992; Nordström et al, 1993; Kapur et al, 1998, 2000; Kapur and Seeman, 2001). In humans, this level of occupancy is associated with haloperidol plasma levels of 1-1.5 ng/ml (Nyberg et al, 1995; Kapur et al, 1997) or olanzapine plasma levels of $\sim 10-25 \mathrm{ng} / \mathrm{ml}$ (Kapur et al, 1998, 1999). Furthermore, clinical trials have documented that antipsychotic dosages corresponding to these plasma levels are associated with the desired antipsychotic effect (Perry et al, 1997, 2001; Apiquian et al, 2003; Keefe et al, 2004; Oosthuizen et al, 2004). Consequently, in this study, we sought to obtain plasma levels of $1-1.5 \mathrm{ng} / \mathrm{ml}$ for 
haloperidol and of $10-25 \mathrm{ng} / \mathrm{ml}$ for olanzapine. We chose to use oral administration of both drugs in order to mimic more closely the most common mode of drug administration in humans and because a depot form of olanzapine was not available.

\section{Blood Sampling}

Prior to the study, all animals were trained to enter a transfer box and then a restraining chute so that blood samples could be obtained without sedation, thus minimizing the exposure of animals to ketamine, an NMDAreceptor antagonist that in humans can induce clinical features reminiscent of schizophrenia. All samples were drawn from the femoral vein approximately $7-8 \mathrm{~h}$ after the morning dose in order to obtain trough plasma levels. Assays for haloperidol and olanzapine were performed using high-performance liquid chromatography, with the haloperidol assay based upon electrochemical detection (Gupta et al, 1995) and the olanzapine assay based upon ultraviolet detection (Olesen and Linnet, 1998). Interassay coefficients of variation, as estimated from the results of quality control samples, were $8.9 \%$ for haloperidol and $5.3 \%$ for olanzapine. The lower limit of quantitation for haloperidol was $0.25 \mathrm{ng} / \mathrm{ml}$ and the corresponding value for olanzapine was $2 \mathrm{ng} / \mathrm{ml}$.

\section{Animal Health and Behavior}

No quantitative measures of behavior were obtained during the study, other than those associated with compliance with the drug exposure regimen. Qualitatively, animals in both the haloperidol and olanzapine groups showed signs of mild bradykinesia and sedation that appeared to worsen with increasing dose, and some animals seemed to become more aggressive with time. This aggressive behavior was noted to develop in four of the olanzapine-exposed animals and in two of the haloperidol-exposed animals.

Animals had free access to water, and were fed in the evening after receiving the afternoon dose of drugs to increase the likelihood that they would consume drugcontaining food or drink. All animals were given between 20 and 30 monkey food pellets (Purina Monkey Chow) per day, which was standard for the population of macaque monkeys at the University of Pittsburgh Primate Research Laboratory. Throughout the study, all animals were provided access to other forms of enrichment including seeds for foraging, toys, and fruit and other food treats. Thus, although the animals were not given unlimited access to food, they were not food restricted.

Throughout the study, all animals were regularly monitored by the University of Pittsburgh Veterinary Staff. Over more than 2 years of study, only two animals - both in the olanzapine group - exhibited medical complications: One animal (2846) experienced recurrent episodes of diarrhea, which resolved with bowel rest or metronidazole, and which did not interfere with the animal's drug compliance. The other animal (2836) engaged in self-injurious behavior prior to starting drug treatment. This animal recurrently cut his hands and feet with the canines, and on several occasions required stitches to close wounds. During the study, this monkey also received NSAIDs and pain medication (buprenorphine) on several occasions. The monkey was initially in the sham group, but was switched into the olanzapine group (resulting in a shuffle of four monkeys total in order to keep the means of the body weights matched across groups), immediately before the initiation of olanzapine treatment, on the rationale that the olanzapine might decrease the frequency of self-injurious behavior. However, no olanzapine-related change in this behavior was seen. To address these behavioral problems, the animal was provided with increased human contact, doubling of cage space, and enhanced enrichment, and the cage was moved to an area of decreased stimulation. Under these circumstances, the animal's behavior stabilized. It should be noted that excluding the data from this animal did only change the results marginally and did not alter any conclusion.

\section{Brain Removal and Measurements}

Matched by terminal body weight, monkeys were euthanized in triads - one from each group. All three monkeys of each triad were euthanized on the same day, with the six triads euthanized over a period of 74 days. Each monkey was euthanized by an overdose of pentobarbital $(50 \mathrm{mg} / \mathrm{kg})$ and removal of the fresh brain was completed within approximately $25 \mathrm{~min}$. The weight of the fresh, whole brain was obtained on a calibrated lab scale (PJ3600 DeltaRange, Mettler-Toledo, $\mathrm{OH}$ ) with a precision of $0.01 \mathrm{~g}$. The same scale was used for all subsequent measures (described in detail below). The cerebellum and brainstem were then separated from the cerebrum by a cut through the mesencephalon at the level of the superior colliculi. The cerebrum was split by a sagittal cut through the corpus callosum and the cerebellum and brainstem were similarly bisected. The right half of each brain was cut into slabs $(\sim 5 \mathrm{~mm})$ and frozen fresh in isopentane on dry ice and subsequently stored at $-80^{\circ} \mathrm{C}$. The left cerebellum/brainstem and the cerebrum were immediately placed in ice-cold $0.1 \mathrm{M}$ phosphate buffer, $\mathrm{pH}=7.3$.

After $5 \mathrm{~min}$ in the buffer, the left cerebrum was dissected into four pieces following the gyration pattern: (1) The frontal piece was removed by cutting (locally perpendicular to the pial surface) through the superior frontal gyrus and the anterior cingulate gyrus at the level of the central sulcus, within the corpus callosum along its dorsal and rostral edge, at the bottom of the central sulcus, along the rostral part of the circular sulcus of the insula, and around the temporal pole. During this procedure, the striatum was split. (2) The occipital piece was removed by a planar cut through the bottom of the lunate sulcus and extending to the medial surface of the hemisphere. (3) The parietal piece was separated from the remainder of the brain by cutting through the corpus callosum along its dorsal edge, at the bottom of the lateral fissure, and through the angular gyrus. (4) The remaining piece consisted of the temporal lobe, insula, and most of the basal ganglia, including the entire thalamus.

When the dissection was complete, the five pieces from the left hemisphere were individually blotted dry and weighed, and their volumes determined by Archimedes' principle of fluid displacement. We used a high-precision approach (Figure 1), in which the weight of the displaced 


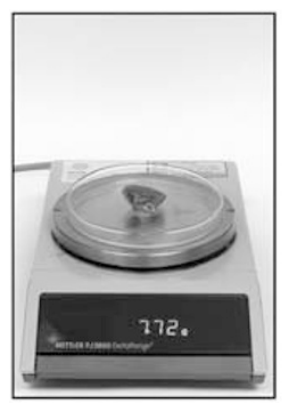

$\mathrm{W}=7.72 \mathrm{~g}$

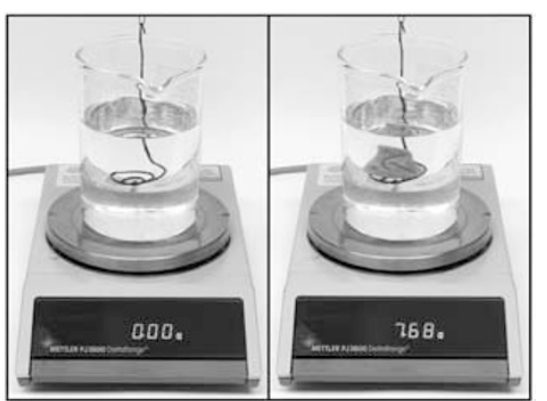

$V=\frac{W_{d}}{\rho_{d}}=\frac{7.68 \mathrm{~g}}{1.14 \mathrm{~g} / \mathrm{cm}^{3}}=6.74 \mathrm{~cm}^{3}$
Figure I Measurement of tissue weight and volume. Left: The tissue piece is weighed at the scale. Right: The principle of Archimedes ad modum Scherle (1970). A beaker containing a fluid is placed on the scale, the tissue supporter is inserted into the fluid to a mark on the handle, and the scale is reset to zero, preventing the volume of the supporter from biasing the measure. Then, the tissue piece on the supporter is lowered into the fluid to the mark, and the readout of the scale indicates the weight of the displaced fluid. The volume of the displaced fluid (ie the volume of the tissue piece) is then calculated using the density of the fluid. $W$ and $V$ are weight and volume of the tissue piece, and $W_{\mathrm{d}}$ and $\rho_{\mathrm{d}}$ are weight and density of the displaced fluid (storing solution in this example).

fluid is measured (Scherle, 1970; Weibel, 1979). The pieces were then placed in ice-cold $4 \%$ paraformaldehyde in $0.1 \mathrm{M}$ phosphate buffer ( $\mathrm{pH}$ 7.4) for $48 \mathrm{~h}$, washed in a graded series of sucrose solutions $(12,16$, and $18 \%)$, and stored in an antifreeze solution (30 vol\% ethylene glycol and $30 \mathrm{vol} \%$ glycerin in $0.024 \mathrm{M}$ phosphate buffer) at $-30^{\circ} \mathrm{C}$. The postmortem interval (PMI, time from death to immersion into fixative) for the left hemisphere pieces was kept at approximately $72 \mathrm{~min}$ for all 18 brains.

To assess the tissue deformation (predominantly shrinkage) introduced by these tissue-processing procedures, the weight and volume of each piece were determined, using the approach described above, at every major step in the tissue processing (ie fresh, after $48 \mathrm{~h}$ of fixation, after $\sim 12$ days in sucrose solutions, after $\sim 11$ days in storing solution at $4{ }^{\circ} \mathrm{C}$, and finally after approximately 1 year in storing solution at $-30^{\circ} \mathrm{C}$ ). Storing solution was used for the fluid displacement in the final measure, while all the previous measures were made in $0.1 \mathrm{M}$ phosphate buffer.

\section{Stereological Assessment of Parietal Piece Volumes}

The volumes of gray and white matter in the parietal pieces were estimated using Cavalieri's principle (Gundersen and Jensen, 1987; Howard and Reed, 1998). The parietal pieces (equilibrated in storing solution) were embedded in agar - 7\% low-melt agarose (SeaPlaque Agarose, Cambrex, Rockland, $\mathrm{ME}$ ) in storing solution - and cut into $2.5-\mathrm{mm}$ thick slabs perpendicular to the intraparietal sulcus. The slicing procedure ensured that all cuts had a systematic, uniformly random position within each tissue piece. The slabs were returned to storing solution and coded as to subject number and group. The resulting cut surfaces of the slabs (12-15 slabs per brain) were observed using a Nikon SMZ1500 Stereoscopic Zoom Microscope, mounted on a Nikon CDSDF diascopic stand F, illuminated from above by fiber optic light from a $150 \mathrm{~W}$ Tungsten Halogen Light Source
(Schott-Fostec, Auburn, NY), and equipped with a $0.5 \times \mathrm{HR}$ Plan Apo Nikon objective, a Nikon DN100 Digital Net Camera $(1280 \times 960$ pixels $)$, and a Triniton Multiscan G420 color monitor. Each cut generates two cut surfaces, which obviously are mirror images of each other. Owing to the overall spindle shape of the parietal pieces, most slabs had a conical appearance where one cut surface was bigger than the other. It turned out to be very difficult to tell the exact outer boundary of the smaller cut surface due to overprojection of the larger cut surface through the transparent agar matrix. Therefore, the caudal surfaces of the rostral slabs were observed until the maximum total area was reached; the slab with maximal area was ignored; and the rostral surfaces of the caudal slabs were observed. In this way, each cut was observed using the cut surfaces that were the larger on its slab and therefore not biased by overprojection. All slabs were observed by one investigator (blind to exposure status) at a final magnification of $9 \times$ at the monitor. A square point grid printed on a transparency was superimposed uniformly random over the monitor image of each cut surface. The areas of gray and white matter observed at each cut surface were estimated from the number of points hitting the gray or white matter, respectively. From these counts, the gray and white matter volumes for each parietal piece were estimated as:

$$
\begin{aligned}
V: & =T \sum A_{i} \\
& =T a \sum P_{i}
\end{aligned}
$$

where $T=2.5 \mathrm{~mm}$ is the mean slab thickness, $a=2.29 \mathrm{~mm}^{2}$ is the area per point of the point grid (corrected for magnification), $A_{i}$ is the gray or white matter area of the $i$ th cut surface, and $P_{i}$ is the respective number of points hitting gray or white matter. For each parietal piece, on average a total of 430 points were counted over gray matter and 215 over white matter. The corresponding mean coefficients of error, CE, were estimated to be 0.02 for the gray matter volumes, 0.03 for the white matter volumes, and 0.01 for the combined total volume using the methods of Gundersen et al $(1987,1999)$.

\section{Precision and Accuracy of the Archimedean Approach}

In order to assess the precision of the weight and Archimedean measurements, we performed two sets of measurements for the 15 pieces from one triad of monkeys. The measurements were obtained by the same person, morning and afternoon of the same day, using samples from the same batch of storing solution for displacement. However, the tissue pieces were returned to the freezer, the scale recalibrated, and the glassware changed between the measurements. The concordance of the remeasured weights and volumes (Figure 2) indicated a very high level of precision corresponding to a $\mathrm{CE} \approx 0.004$ for both weights and volumes.

In order to assess the accuracy of the Archimedean measurements, we measured the volume of all 18 parietal pieces immediately before embedding in agar. In this way, we could compare the total volume measures obtained by the Archimedes' principle to corresponding volume estimates obtained by Cavalieri's principle. To measure the inter-rater reliability of the Archimedean measurements, 


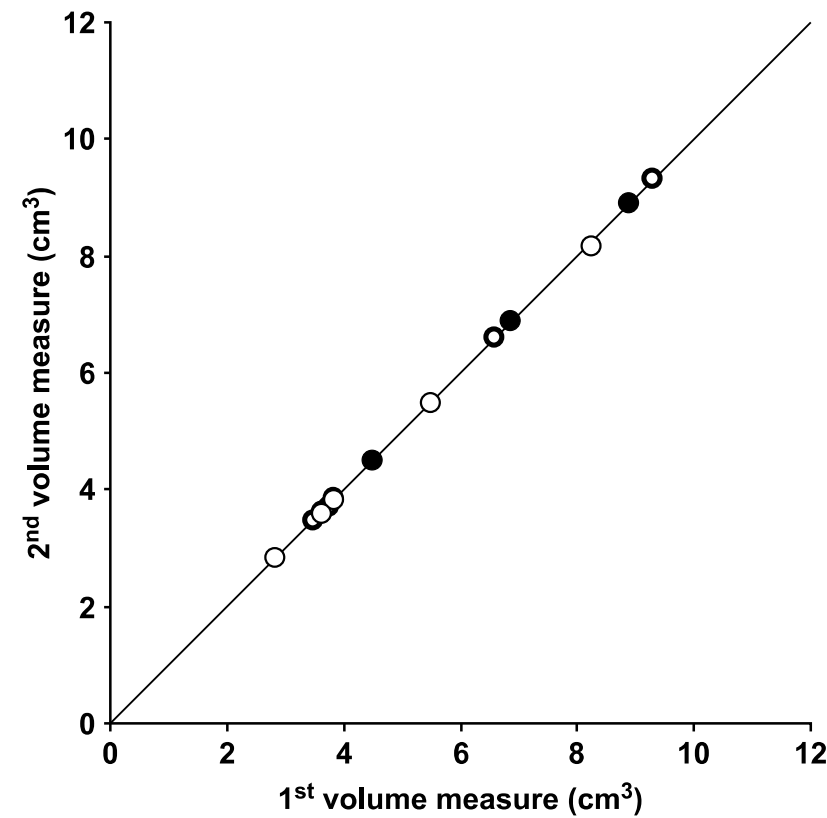

Figure 2 Precision of the Archimedean volume measures as demonstrated by 15 pairs of observations. Filled circles indicate sham; thin open circles, haloperidol; and thick open circles, olanzapine. Line is the identity line.

two observers measured the same 15 tissue pieces at the same time, but blind to each other. The intraclass correlation coefficient of 0.9998 (95\% confidence interval, 0.9993-0.9999) illustrated that our Archimedean measurements are as reliable as weighing the tissue. The weight and the Archimedean measures were performed by several observers who were not formally blind to the exposure status. Owing to the very high inter-rater reliability, precision, and accuracy of the methods, we judged there were virtually no room for any observer bias and no need for blinding at this initial stage.

\section{Statistics}

To examine the difference in initial body weight and age of the animals at the time of euthanasia among exposure groups (sham, haloperidol, and olanzapine), one-way analysis of variance (ANOVA) models were used, with the exposure group as the main effect. To explore the differences in terminal body weight among the three groups, an analysis of covariance (ANCOVA) model was used, with group as the main effect and initial body weight as a covariate.

One-way ANOVA models with the exposure group as the main effect were performed to examine the differences among the three groups for each primary response variable. For the multiple comparisons procedure, which compared both drug exposed groups with the sham group, we used Dunnett's procedure (Hochberg and Tamhane, 1987).

To examine the robustness of the ANOVA conclusions, the Kruskal-Wallis test, a nonparametric alternative to the one-way ANOVA, was carried out to test the group effect for each response variable. As a nonparametric analogue of the Dunnett's multiple comparisons procedure in one-way
ANOVA, Steel's procedure (Hochberg and Tamhane, 1987) was used to confirm results of the comparisons of the drugexposed groups with the sham group.

A two-way ANOVA model was employed to analyze the main group effect and the triad blocking effect on the change in the left brain volume as a result of tissue processing. Multiple comparisons among triads used Tukey's procedure (Neter et al, 1996). To examine the difference in shrinkage among the five regions of the brain, the multivariate analysis of variance (MANOVA) model based on repeated measures with a compound symmetric covariance structure (Littell et al, 1996) was used with exposure group as the main effect, triad as a blocking effect, and region as a within-subject effect. Regions were compared using the Bonferroni multiple comparisons procedure.

Analyses were implemented in SAS PROC GLM (SAS Institute Inc., 1990), SAS PROC MIXED (Littell et al, 1996), and SAS PROC NPAR1WAY (SAS Institute Inc., 1990). F-tests for the effect of diagnostic group are based on type III sum of squares. An alpha level of 0.05 was selected as indicator of significance for all tests and multiple comparisons.

\section{RESULTS}

\section{Monkey Model of Chronic Antipsychotic Drug Exposure}

The doses of haloperidol and olanzapine were gradually increased (Figure 3, top), until the monkeys were receiving 24-28 mg of haloperidol or 11.0-13.2 mg of olanzapine per day. The final trough drug plasma levels were $\sim 1.5 \mathrm{ng} / \mathrm{ml}$ for haloperidol and $\sim 15 \mathrm{ng} / \mathrm{ml}$ for olanzapine (Figure 3, bottom). Neither the initial (by design) nor the terminal mean body weight of the monkeys differed significantly across the groups. Mean (coefficient of variation $\mathrm{CV}=\mathrm{SD}$ / mean) initial body weights were $4.40(0.21) \mathrm{kg}, 4.12$ $(0.14) \mathrm{kg}$, and $4.12(0.29) \mathrm{kg}$ for the sham, haloperidol, and olanzapine groups, respectively. The corresponding mean (CV) terminal body weights were $6.05(0.20) \mathrm{kg}, 6.13$ $(0.20) \mathrm{kg}$, and $6.05(0.12) \mathrm{kg}$. Most animals did increase substantially in weight during the experimental period (Figure 4), consistent with the expected growth of male animals of this species and age. The mean (CV) age of the animals at time of euthanasia did not differ $\left(\mathrm{F}_{2,15}=0.48\right.$, $p=0.63)$ and were $84.0(0.03)$ months, 85.2 (0.05) months, and 83.1 (0.04) months for the sham, haloperidol, and olanzapine groups, respectively.

\section{Fresh Brain Weight and Volume}

The mean fresh brain weights differed significantly among the three exposure groups $\left(\mathrm{F}_{2,15}=3.99, p=0.041\right)$, with those of the haloperidol $(\mathrm{H})$ and olanzapine $(\mathrm{O})$ groups $8.1 \%$ and $9.6 \%$, respectively, lower than that of the sham (S) group (Figure 5). The fresh weight and volume of the left cerebrum were calculated for each brain as the sum of the respective measures of the four cerebral tissue pieces, as this was the most anatomically well-defined unit in the study. Mean fresh left cerebral weights differed significantly $\left(\mathrm{F}_{2,15}=4.85, p=0.024\right)$ among the groups; weights of the 

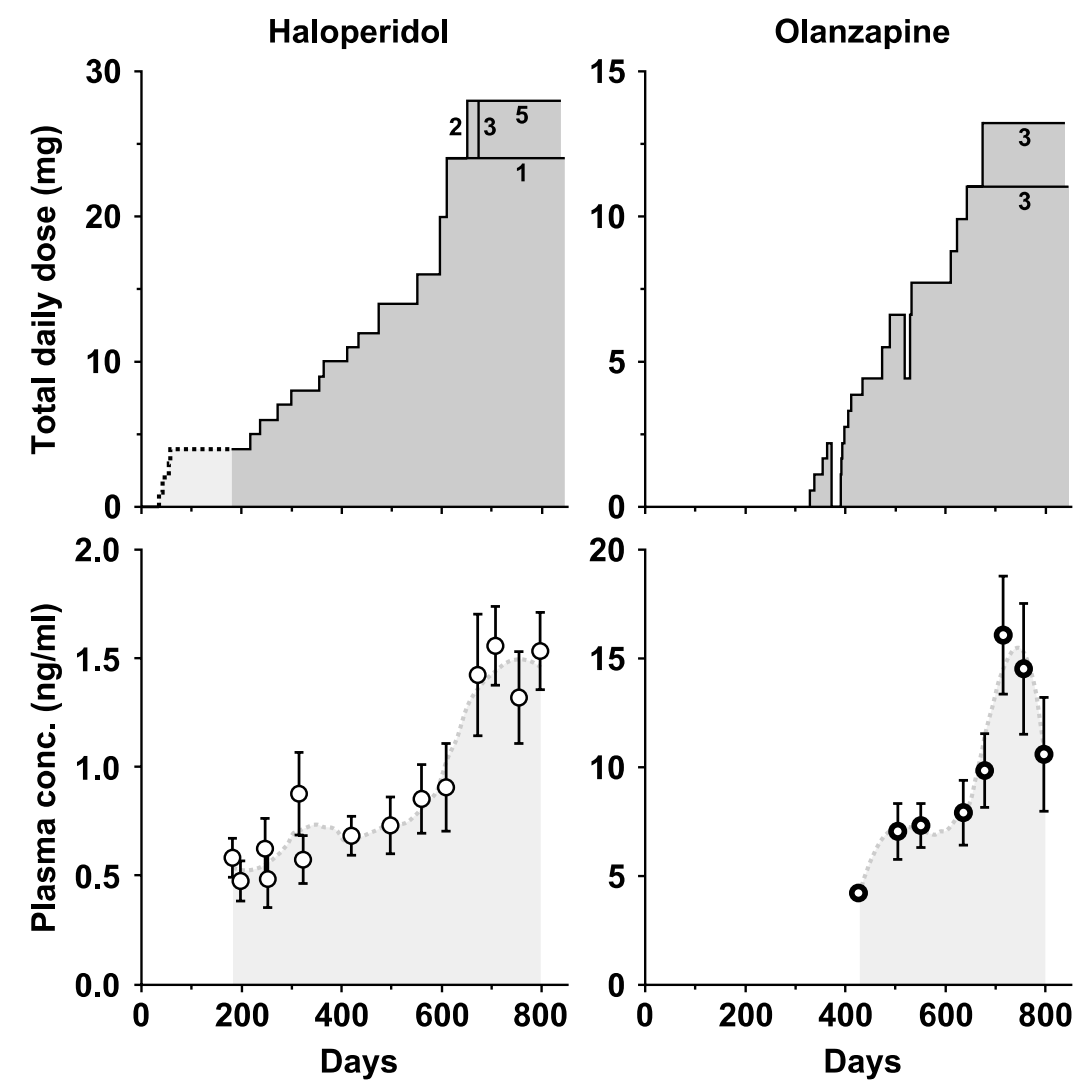

Figure 3 Top: Administrated daily drug dose as a function of time for each monkey in the haloperidol- (left) and olanzapine- (right) exposed groups. Numbers within each plot indicate how many monkeys received that drug dose. For example, at day 65I, two monkeys were raised to a final haloperido dosage of $28 \mathrm{mg} / \mathrm{day}$, and 23 days later, additional three animals were raised to that level. The punctuated line and the light gray area at the beginning of the haloperidol graph indicate the initial period with drug administration limited to 5 days a week. Bottom: Mean trough plasma levels of the respective drug for the six monkeys in each group. The error bars indicate the standard error of the mean for each group at each time point. The plots at the bottom terminate earlier than the plots at the top because the monkeys were euthanized (in triads) over a 74-day period.

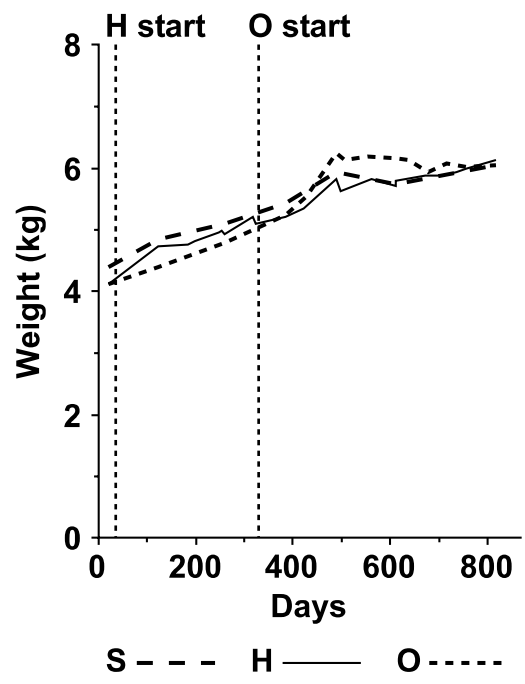

Figure 4 Increase in mean body weights for each group ( $\mathrm{S}$, sham; $\mathrm{H}$, haloperidol; $\mathrm{O}$, olanzapine) across the course of the study. Vertical lines indicate the time points when each of the two drugs was introduced. The mean (CV) percentage gain in weight for each group was: sham, 38\% (0.37); haloperidol, 53\% (0.79); olanzapine, 53\% (0.53).

$\mathrm{H}$ and $\mathrm{O}$ groups were $8.9 \%$ and $10.9 \%$ lower, respectively, than the S group (Table 1). The corresponding mean fresh left cerebral volumes showed virtually the same pattern: $\mathrm{H}$

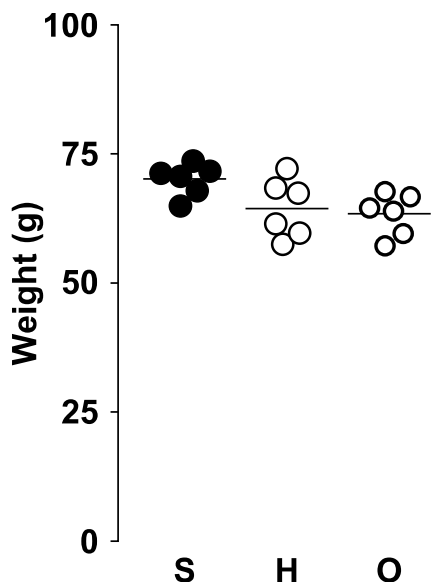

Figure 5 Fresh brain weights for the sham- $(S)$, haloperidol- $(H)$ and olanzapine- $(O)$ exposed monkeys. The horizontal bars indicate group means.

vs $\mathrm{S}$ decreased by $8.8 \%$ and $\mathrm{O}$ vs $\mathrm{S}$ decreased by $10.5 \%$ $\left(\mathrm{F}_{2,15}=4.70, p=0.026\right)$.

Comparison of mean fresh weights of individual tissue pieces suggested that the differences were more robust in the frontal and parietal regions (Figure 6). Specifically, the mean weight of the frontal piece was significantly $\left(\mathrm{F}_{2,15}=4.55, p=0.029\right)$ lower by $10.1 \%$ and $10.4 \%$ in the 
$\mathrm{H}$ and $\mathrm{O}$ groups, respectively, relative to $\mathrm{S}$; for the parietal piece, $\mathrm{H}$ was decreased by $11.2 \%$ and $\mathrm{O}$ was decreased by $13.6 \%\left(F_{2,15}=5.20, p=0.019\right)$ relative to $S$. The other three regions followed the same general pattern, but the differences did not achieve statistical significance: temporal, $\mathrm{H} v s \mathrm{~S}$ decreased by $6.9 \%$ and $\mathrm{O} v s \mathrm{~S}$ decreased by $10.5 \%$ $\left(\mathrm{F}_{2,15}=2.31, p=0.13\right)$; occipital, $\mathrm{H}$ vs $\mathrm{S}$ decreased by $9.7 \%$ and $\mathrm{O}$ vs $\mathrm{S}$ decreased by $9.8 \%\left(\mathrm{~F}_{2,15}=0.60, p=0.56\right)$; and cerebellum and brainstem, $\mathrm{H}$ vs $\mathrm{S}$ decreased by $8.7 \%$ and $\mathrm{O}$ $v s \mathrm{~S}$ decreased by $8.5 \%\left(\mathrm{~F}_{2,15}=0.92, p=0.42\right)$. The pattern for the corresponding volumes was virtually identical, indicating only minor variability in the tissue density within the same brain region across the monkeys. Results of the multiple comparisons procedure are shown for all significant ANOVAs in Figure 7.

\section{Changes in Brain Weight and Volume during Tissue Processing}

During the first four phases of tissue processing, brain weight and volume decreased in an identical manner across the three exposure groups (Figure 8). Over time in storing solution, brain weight and volume partially returned to initial values. The mean final tissue shrinkage due to tissue processing was $20.5 \%(C V=0.13)$ and was virtually identical $\left(\mathrm{F}_{2,10}=1.02, p=0.39\right)$ across the three groups of animals (Table 2). However, we observed a significant difference in final shrinkage across the six triads $\left(\mathrm{F}_{5,10}=13.31, p=0.0004\right)$, with the brains from the monkeys of the first triad shrinking significantly less than the five other triads, even though the experimental protocol did not differ across triads. Additionally, a marked difference in shrinkage pattern was observed across the five tissue regions $\left(\mathrm{F}_{4,68}=71.31, p<0.0001\right)$. Pair-wise comparisons indicated significant differences in the amount of shrinkage

Table I Mean (CV) Fresh Weight and Volume of the Left Cerebrum for Each Group of Animals

\begin{tabular}{lcc}
\hline & Weight $\mathbf{( g )}$ & Volume $\left.\mathbf{( c m}^{\mathbf{3}}\right)$ \\
\hline Sham & $30.53(0.03)$ & $29.37(0.03)$ \\
Haloperidol & $27.80(0.10)$ & $26.79(0.09)$ \\
Olanzapine & $27.20(0.07)$ & $26.28(0.07)$ \\
\hline
\end{tabular}

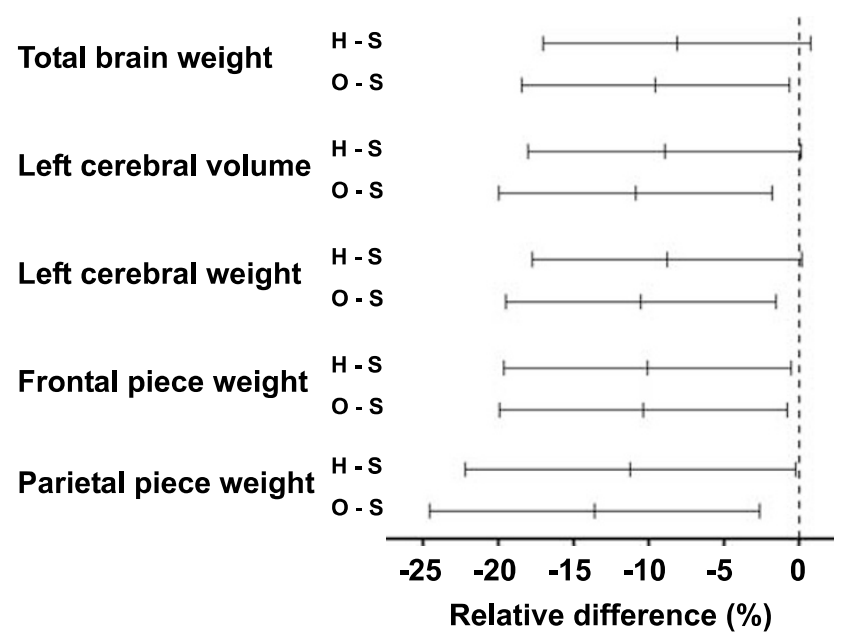

Figure 7 The 95\% confidence intervals for the relative difference of each exposure group (haloperidol, $\mathrm{H}$; olanzapine, O) vs sham group (S) calculated using Dunnett's method for each variable that reached significance in the main ANOVAs. For those intervals that cross the origin, the difference between groups did not reach the 0.05 significance level.

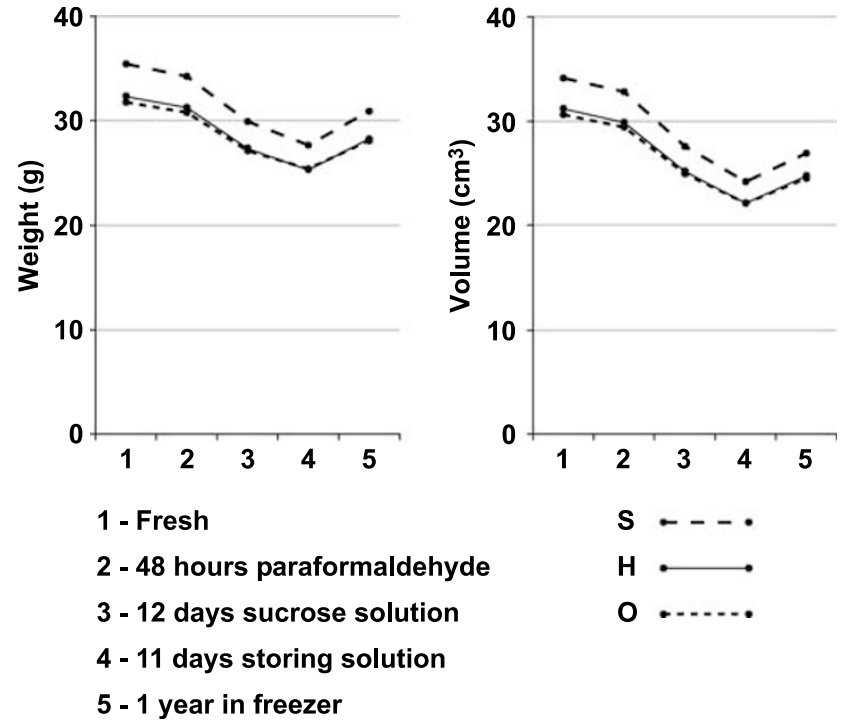

Figure 8 Plots of the mean weight (left) and volume (right) of the entire left hemisphere at specific stages in tissue processing for the sham- (S), haloperidol- $(\mathrm{H})$ and olanzapine- $(\mathrm{O})$ exposed monkeys.

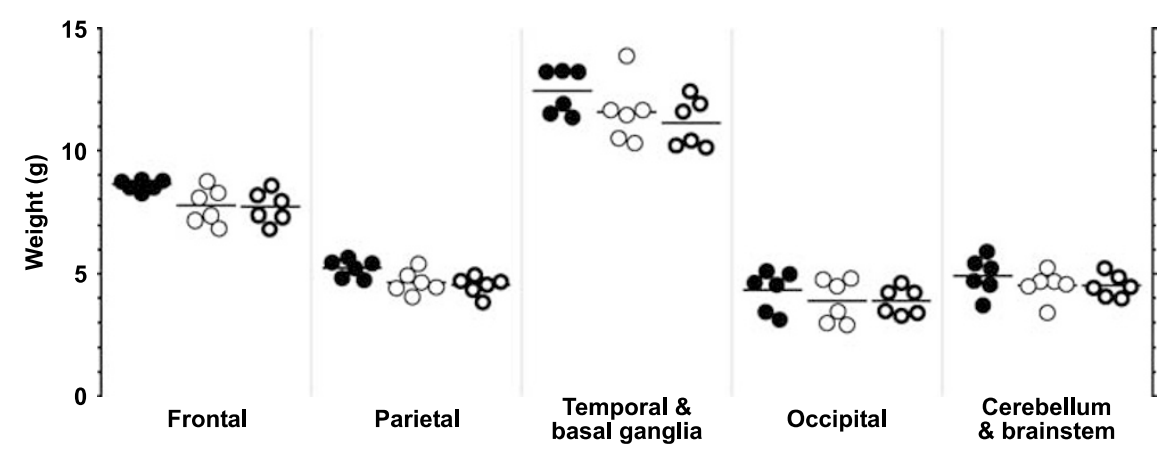

Figure 6 Fresh weights of the individual tissue pieces from the left brain of the monkeys of the sham- (filled circles), haloperidol- (thin open circles) and olanzapine- (thick open circles) exposed groups. The horizontal bars indicate group means. 
Table 2 Mean (CV) Final Shrinkage of Brain Regions and of the Whole Left Brain for Each Group

\begin{tabular}{lccc}
\hline Region & Sham & Haloperidol & Olanzapine \\
\hline Temporal-basal ganglia & $25.1 \%(0.15)$ & $23.5 \%(0.13)$ & $23.6 \%(0.11)$ \\
Frontal & $21.7 \%(0.15)$ & $21.8 \%(0.17)$ & $21.0 \%(0.17)$ \\
Cerebellum-brainstem & $18.9 \%(0.19)$ & $17.8 \%(0.17)$ & $16.6 \%(0.13)$ \\
Parietal & $16.7 \%(0.14)$ & $17.1 \%(0.08)$ & $16.8 \%(0.11)$ \\
Occipital & $15.3 \%(0.18)$ & $15.3 \%(0.13)$ & $15.2 \%(0.09)$ \\
Whole left brain & $21.0 \%(0.15)$ & $20.5 \%(0.14)$ & $20.0 \%(0.12)$ \\
\hline
\end{tabular}

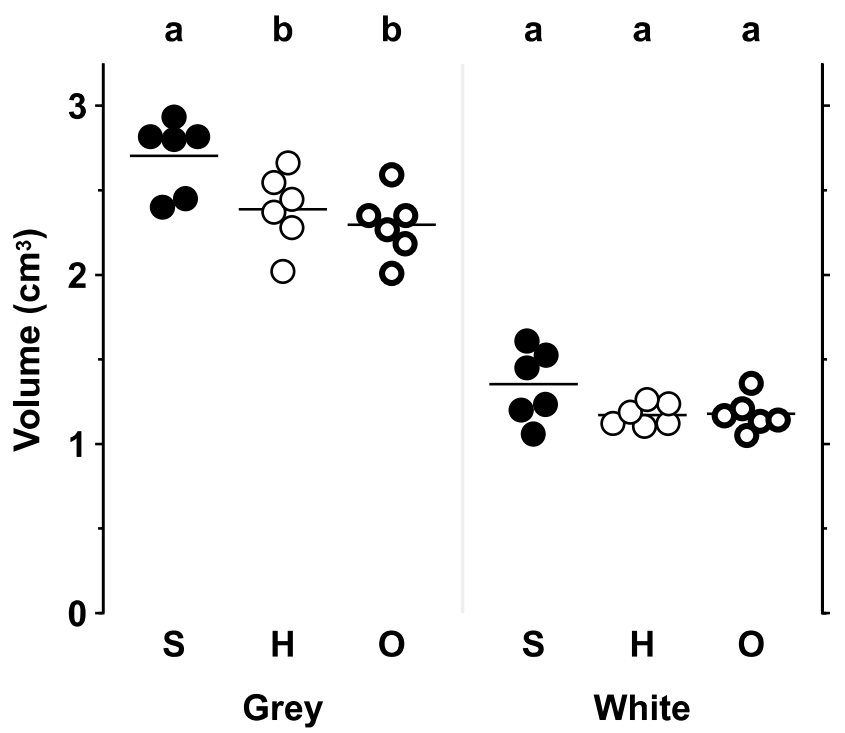

Figure 9 Gray and white matter volume in the parietal pieces determined by Cavalieri's principle for each of the sham- (S), haloperidol$(\mathrm{H})$ and olanzapine- $(\mathrm{O})$ exposed monkeys. The horizontal bars indicate group means. Lettering at the top indicates the results of Dunnett's procedure; regions not sharing the same letter are significantly different at $p<0.05$.

across regions, with the greatest shrinkage occurring in the temporal-basal ganglia piece and the least in the occipital region (Table 2).

\section{Gray and White Matter Volume of the Parietal Region}

In order to determine whether the reductions in brain volume observed in the $\mathrm{H}$ and $\mathrm{O}$ animals reflected changes in gray and/or white matter volumes, we estimated the volumes of these compartments in the stored parietal pieces (Figure 9). The mean gray matter volume was significantly $\left(\mathrm{F}_{2,15}=6.12, p=0.011\right)$ reduced in the $\mathrm{H}(11.8 \%)$ and $\mathrm{O}$ $(15.2 \%)$ compared to $S$, while similar decreases in mean white matter volume $(\mathrm{H}, 13.3 \% ; \mathrm{O}, 12.7 \%)$ almost reached significance $\left(\mathrm{F}_{2,15}=3.03, p=0.079\right)$.

\section{Accuracy of the Archimedean Approach}

In order to verify the accuracy of the Archimedean volume measurement, we assessed the volumes of the parietal pieces using two different methods (Archimedes'vs Cavalieri's

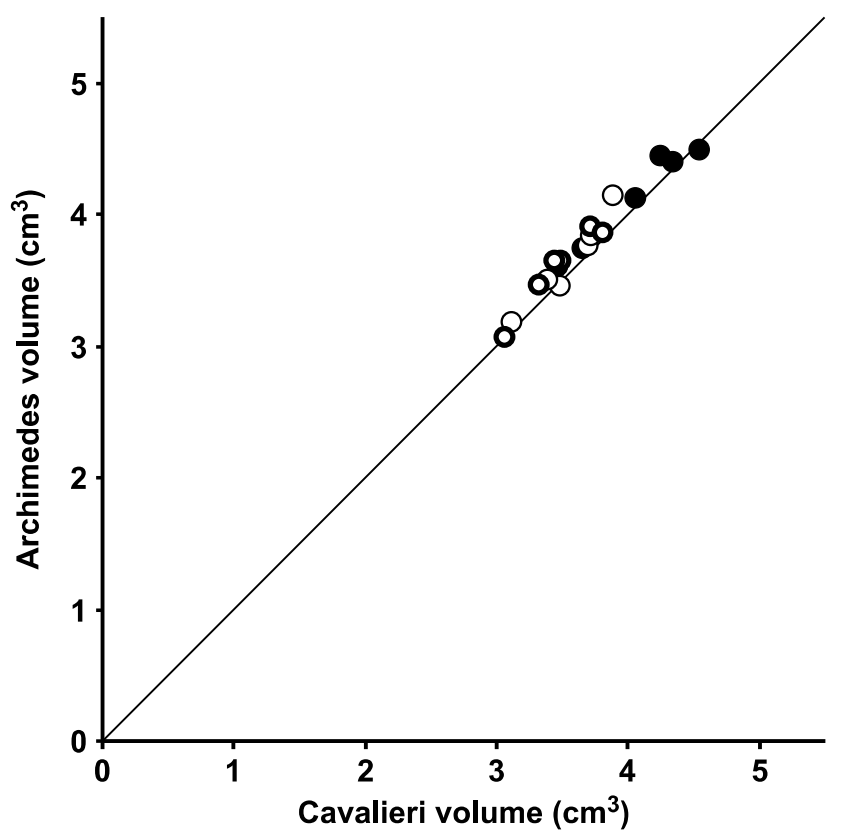

Figure 10 Comparison of the volume measures of the parietal pieces obtained by Archimedes' principle and Cavalieri's principle for each of the I 8 animals. Filled circles indicate sham; thin open circles, haloperidol; and thick open circles, olanzapine. Line is the identity line.

principle). The comparison of Cavalieri estimates and Archimedean measures of total parietal volume indicated a high degree of concordance with a small systematic difference; the Archimedean measures were larger by an average of $2.9 \%$ (Figure 10 ), without a systematic difference in bias across the exposure groups.

\section{DISCUSSION}

\section{Effects of Haloperidol and Olanzapine on Brain Weight and Volume}

In the present study, we observed smaller brain weights and volumes in male macaque monkeys after 1.5-2.3 years of exposure to haloperidol or olanzapine at plasma drug levels comparable to those in treated humans. Exposure to either of the drugs was associated with a similar reduction in mean fresh brain weight, as well as mean fresh weight and volume of the left cerebrum, compared to matched, placeboexposed animals. For both drugs, the magnitude of these effects was in the range of $8-11 \%$. The reduction seemed to be global (ie including all brain regions), but was most robust in the frontal and parietal lobes. In addition, both gray and white matter volumes appeared to be reduced to a similar degree.

Several factors must be considered when interpreting the results. First, although macaque monkeys provide a more relevant brain model for human studies than do rodents, they metabolize antipsychotic drugs differently than humans. For example, approximately $55 \%$ of an oral dose of olanzapine is absorbed in monkeys $v s$ at least $65 \%$ in humans; the terminal elimination half-life is $\sim 3 \mathrm{~h}$ in monkeys $v s \sim 27 \mathrm{~h}$ in humans; and due to different metabolic pathways, the plasma levels of the various 
metabolites of unknown bioactivity are quite likely very different (Kassahun et al, 1997; Mattiuz et al, 1997). Likewise, haloperidol is metabolized markedly faster by monkeys than humans (JM Perel and L Roizin, personal communication). Consistent with these differences in metabolism, the doses (in $\mathrm{mg} / \mathrm{kg}$ ) required in reaching comparable drug plasma levels were substantially higher in monkeys than those used in humans.

Second, it is not clear how an apparent drug effect on the brain of monkeys translates to humans with schizophrenia or other brain disorders. Specifically, we cannot conclude that normal human brains would show the same changes in weight and volume as monkeys, and if they do, whether the effect would be of the same, greater, or smaller magnitude in individuals with brain disorders. Finally, we cannot infer from this study whether such changes represent a beneficial, unwanted, or incidental effect.

To our knowledge, previous structural studies of primates exposed to antipsychotic medication have not assessed either total fresh or fixed volumes or weights (Akil et al, 1999; Pierri et al, 1999; Selemon et al, 1999), although all assume, based on cortical thickness measures, that no cortical volume loss occurred. However, a volume loss of $\sim 10 \%$ as seen here corresponds to a linear change of $\sim 3 \%$, the detection of which requires more accurate and precise measurements than previously used. In this context, it should be mentioned that each of these previous studies based their structural analyses on density measures, which are known to be very sensitive to volume changes (Mendis-Handagama and Ewing, 1990). For example, both the increased 2-D densities of GAT-1-immunoreactive cartridges reported by Pierri et al (1999), and the increased glial 3-D densities reported by Selemon et al (1999) associated with antipsychotics, are very difficult to interpret unambiguously without measures of total cartridge or glia number and the corresponding reference volume. In light of our findings, the increased densities reported by these two studies could be a result of a reduction in the reference volume.

\section{Potential Sources of the Observed Reductions in Brain Volume}

What happened to the brain volume in our monkeys? Regions enriched in dopamine $\mathrm{D}_{2}$ receptors might be hypothesized to be preferentially affected. However, due to the tissue-blocking procedure (see next section), it is not possible from our data to determine whether regions enriched in dopamine $\mathrm{D}_{2}$ receptors were predominantly affected. As both the gray and white matter appeared to be reduced to a similar degree in the parietal piece, the most parsimonious explanation of the findings would be a change in a structural element common to both compartments, that is, involving neurons and their processes (axons and dendrites), glia cells, and/or the vascular bed. Owing to the limited number of non-human primate studies, the following discussion is to a large degree based upon what we know from human studies.

The observed differences could be due to a decrease in the number or size of one or several types of neurons. Modern stereological studies of total neuron number in a range of brain regions have not found evidence of a deficit in neuronal number in subjects with schizophrenia (most of whom had been treated with antipsychotics) (Heckers et al, 1991; Pakkenberg, 1993; Thune et al, 2001; Andersen and Pakkenberg, 2003). Even the seemingly robust findings of reduced neuronal number in the mediodorsal thalamic nucleus previously reported by several groups have recently been questioned (Cullen et al, 2003; Dorph-Petersen et al, 2004; Young et al, 2004). On the other hand, studies of various brain regions in (predominantly medically treated) subjects with schizophrenia have reported decreased somal cell volumes (Benes et al, 1991; Arnold et al, 1995; Rajkowska et al, 1998; Pierri et al, 2001; Sweet et al, 2003, 2004), suggesting that a treatment-related reduction in neuronal size (with associated reductions in dendritic and axonal arbors) may be present. However, although consistent, these neuronal somal size studies should be interpreted with some care as none of these studies fully applied unbiased stereological methods of sampling and measurement. In addition, a recent stereological study of brains from males chronically treated with antipsychotics did not find reductions in the total length or diameter of myelinated nerve fibers in prefrontal or global white matter (Marner and Pakkenberg, 2003). However, as unmyelinated fibers were not investigated, a change in these could not be ruled out.

Alternatively, the observed volume reduction could be due to changes in glia cells. Interestingly, several psychiatric disorders have been reported to have decreased glia cell number or density (Cotter et al, 2001, 2002; Rajkowska et al, 2001; Hof et al, 2003; Stark et al, 2004). However, additional studies are needed to determine whether these observed glial changes are specific to the respective diseases or related to treatment with antipsychotic drugs. A growing body of literature describes abnormalities in myelination in schizophrenia (Davis et al, 2003), although again it is not clear to what degree these findings reflect treatment with antipsychotics.

Another candidate for structural changes in both white and gray matter may be the vascular bed. However, as studies of different brain regions in different species have consistently found that the vascular bed comprises less than $5 \%$ of the total brain volume (Haug, 1986; Weis et al, 1996; L $\varnothing$ kkegaard et al, 2001), a reduction in the vascular bed could contribute to, but not fully account for, the observed volume reductions.

\section{Implication for Studies of Schizophrenia}

The results of this study raise the possibility that reported findings of progressive reductions in the volume of certain brain regions in individuals with schizophrenia may be confounded by a treatment effect. A recent meta-analysis of post-mortem studies found a small $(2 \%)$ but significant decrease in brain weight in schizophrenia (Harrison et al, 2003). Correspondingly, only 11 out of 50 imaging studies found reduced whole brain volume in schizophrenia (Shenton et al, 2001); however, all 11 of the positive studies were based upon chronic patients, while 10 of the negative studies were based upon subjects in their first episode of schizophrenia. In addition, it is not clear to what degree the inconsistency of the MRI findings reflects methodological limitations; assessments of accuracy of MRI-based volume 
estimates suggest that significant biases may be present (Gadeberg et al, 1999, 2002; Garcia-Fiñana et al, 2003). Assuming it exists, this small difference could to some degree be caused by medication effects like the one observed in this study; however, it appears that a medication-induced difference in whole brain size of a magnitude comparable to the $\sim 10 \%$ seen in our study does not occur, in general, in individuals with schizophrenia treated with antipsychotic drugs. It should also be noted, though, that a medication effect could be diluted by heterogeneities in subject populations as well as in treatment regimens. In addition, potential drug effects may show a more regional pattern in the human brain, compared to the monkey, again diluting the overall effects. Indeed, longitudinal imaging studies typically have reported progressive changes localized to specific brain regions such as reduced volume of middle temporal lobe (Okubo et al, 2001; Shenton et al, 2001; Niznikiewicz et al, 2003). Interestingly, a recent post-mortem schizophrenia study found a selective and significant $12 \%$ reduction in frontal gray matter volume and a $6 \%$ reduction in frontal white matter (Selemon et al, 2002), findings in the same range as those found in the current study.

Longitudinal imaging studies have reported increased volume of the caudate nucleus in humans treated with typical antipsychotics (Chakos et al, 1994; Keshavan et al, 1994; Doraiswamy et al, 1995), whereas reduced or unchanged caudate volume has been seen in subjects treated with atypical antipsychotics (Chakos et al, 1995; Gur et al, 1998; Corson et al, 1999; Scheepers et al, 2001). This pattern has been replicated in a recent stereological study of rats, where haloperidol exposure was associated with an increased volume of striatum and olanzapine exposure with a reduction (Andersson et al, 2002). Interestingly, a recent study of subjects with schizophrenia treated with low dosage haloperidol or atypical antipsychotics and normal comparison subjects found similar decrease in volumes of the caudate nucleus in all three groups after a 5-year follow-up (Tauscher-Wisniewski et al, 2002). Unfortunately, in our study, we have not been able to illuminate these findings. The caudate nucleus was divided into several pieces by the initial, cortex-focused dissection, and the largest part of the caudate was contained within the temporal piece. Furthermore, as the caudate comprised only a minor part of this piece and the reported caudate volume changes in humans were of limited magnitude (within $\pm 15 \%$ ), we do not have the necessary resolution to observe a potential drug-related caudate effect.

\section{Tissue Shrinkage}

Our findings also clearly illustrate how a standard histological protocol for cryoprotection and storage of brain tissue induces a significant shrinkage of $\sim 20 \%$. This shrinkage occurs despite the gradual stepwise increment in sucrose concentration and the relative moderate final concentration of $18 \%$ sucrose; a single step of immersion in $30 \%$ sucrose as used by some laboratories may very well induce a greater degree of tissue shrinkage. The observed shrinkage in the current study was the same across all three groups of animals; we did not see any evidence of either global or regional differences in shrinkage due to drug exposure. It should be kept in mind, however, that our findings cannot rule out a distinct difference in postmortem shrinkage of any minor subcompartment of the tissue (eg of a certain cell type), as such an effect - although pronounced-could be miniscule compared to the total volume and below the resolution of our study. The observation of similar post-mortem shrinkage across all three groups of animals is of importance when interpreting size or density data from human post-mortem studies of subjects treated with antipsychotics. For example, the finding of reduced global or regional brain volumes in subjects with schizophrenia (Pakkenberg, 1987; Selemon et al, 2002) has been discussed under the implicit assumption that the tissue volume was reduced in vivo, without considering the possibility that the brains from subjects with schizophrenia shrunk more during tissue processing. Finally, we observed that different brain regions shrunk differently. This might very well be due to regional differences in structure (such as white and gray matter content), volume, shape, and total external surface (natural and/or cut) - characteristics that are all of obvious importance for the exchange of fluids (predominantly water) that is likely the main cause of the processinginduced shrinkage. This indicates that the use of a global (whole brain) shrinkage correction factor for studies of a particular brain region should be avoided or only implemented and interpreted with very great care.

\section{Precision and Accuracy of the Quantitative Approach}

In the present study, we have documented that the implementation of Archimedes' principle is both precise and accurate. Although both Archimedes' and Cavalieri's methods for volume determination are unbiased in principle, they are of course potentially biased in implementation. The Archimedean approach was expected to have a small positive bias due to fluid or small air bubbles trapped in sulci at the surface of the tissue pieces, whereas the results based upon Cavalieri's principle in the present implementation could have a small negative bias due to under projection. The fact that potential biases of the two methods were of opposite directions is crucial for the comparison of the Archimedean results to those based upon Cavalieri's principle. Consistent with our expectations, we found that the combination of the systematic biases of the two methods is below $3 \%$, indicating that both methods are very accurate. Furthermore, Figure 10 illustrates (as expected) that we did not register any observer biases across exposure groups due to lack of blinding during the last set of Archimedean measures.

The reported Cavalieri volumes of gray and white matter are influenced to an unknown (but limited) degree by over and under projections at the boundary between white/gray matter (eg a thin layer of white matter over gray matter may go unnoticed and vice versa). We sought to limit this bias as much as possible by cutting the parietal slabs perpendicular to the intraparietal sulcus, thereby minimizing the amount of cuts oblique to the pial surface. Perpendicular cuts are less prone to over- and underprojection problems due to better visualization of the white/gray matter boundary. 


\section{Conclusion}

In summary, we found that chronic exposure of monkeys to haloperidol or olanzapine in a manner that mimics clinical use is associated with a significant reduction in brain volume that affects both gray and white matter. In contrast, although substantial and regionally specific reductions in tissue volume occur with histological processing, pre-mortem exposure to antipsychotics does not appear to affect this process.

Further studies are needed to confirm these observations of antipsychotic-related reductions in brain volume, to identify the affected neural elements, and to determine the mechanisms that produce these changes.

\section{ACKNOWLEDGEMENTS}

We thank Lisa Nieman-Vento, Clara Reiter, Stephan Eggan, and Dustin Hammers for technical assistance, Qiang Wu for assisting with the statistical analysis, Mary Brady for help with graphics, Professor Hans Jørgen G Gundersen for suggestions on the post-mortem experimental design, and Dr Robert A Sweet for helpful comments to this paper. The study received support from The Danish Medical Research Council, USPHS Grants MH45156 and MH43784, and an investigator-initiated grant from Eli Lilly. Dr Allan R Sampson is a statistical consultant for Johnson \& Johnson Pharmaceutical Research \& Development, LLC.

\section{REFERENCES}

Akil M, Pierri JN, Whitehead RE, Edgar CL, Mohila C, Sampson AR et al (1999). Lamina-specific alterations in the dopamine innervation of the prefrontal cortex in schizophrenic subjects. Am J Psychiatry 156: 1580-1589.

Andersen BB, Pakkenberg B (2003). Stereological quantitation in cerebella from people with schizophrenia. $\mathrm{Br} J$ Psychiatry 182: 354-361.

Andersson C, Hamer RM, Lawler CP, Mailman RB, Lieberman JA (2002). Striatal volume changes in the rat following long-term administration of typical and atypical antipsychotic drugs. Neuropsychopharmacology 27: 143-151.

Apiquian R, Fresán A, Herrera K, Ulloa RE, Lóyzaga C, FuenteSandoval C et al (2003). Minimum effective doses of haloperidol for the treatment of first psychotic episode: a comparative study with risperidone and olanzapine. Int J Neuropsychopharmacol 6: 403-408.

Arnold SE, Franz BR, Gur RC, Gur RE, Shapiro RM, Moberg PJ et al (1995). Smaller neuron size in schizophrenia in hippocampal subfields that mediate cortical-hippocampal interactions. Am J Psychiatry 152: 738-748.

Benes FM, Sorensen I, Bird ED (1991). Reduced neuronal size in posterior hippocampus of schizophrenic patients. Schizophr Bull 17: 597-608.

Chakos MH, Lieberman JA, Alvir J, Bilder R, Ashtari M (1995). Caudate nuclei volumes in schizophrenic patients treated with typical antipsychotics or clozapine. Lancet 345: 456-457.

Chakos MH, Lieberman JA, Bilder RM, Borenstein M, Lerner G, Bogerts B et al (1994). Increase in caudate nuclei volumes of first-episode schizophrenic patients taking antipsychotic drugs. Am J Psychiatry 151: 1430-1436.

Corson PW, Nopoulos P, Miller DD, Arndt S, Andreasen NC (1999). Change in basal ganglia volume over 2 years in patients with schizophrenia: typical versus atypical neuroleptics. Am J Psychiatry 156: 1200-1204.
Cotter D, Mackay D, Chana G, Beasley C, Landau S, Everall IP (2002). Reduced neuronal size and glial cell density in area 9 of the dorsolateral prefrontal cortex in subjects with major depressive disorder. Cereb Cortex 12: 386-394.

Cotter D, Mackay D, Landau S, Kerwin R, Everall I (2001). Reduced glial cell density and neuronal size in anterior cingulate cortex in major depressive disorder. Arch Gen Psychiatry 58: 545-553.

Cullen TJ, Walker MA, Parkinson N, Craven R, Crow TJ, Esiri MM et al (2003). A postmortem study of the mediodorsal nucleus of the thalamus in schizophrenia. Schizophr Res 60: 157-166.

Davis KL, Stewart DG, Friedman JI, Buchsbaum M, Harvey PD, Hof PR et al (2003). White matter changes in schizophrenia: evidence for myelin-related dysfunction. Arch Gen Psychiatry 60: 443-456.

Doraiswamy PM, Tupler LA, Krishnan KRR (1995). Neuroleptic treatment and caudate plasticity. Lancet 345: 734-735.

Dorph-Petersen KA, Pierri JN, Sun Z, Sampson AR, Lewis DA (2004). Stereological analysis of the mediodorsal thalamic nucleus in schizophrenia: volume, neuron number, and cell types. J Comp Neurol 472: 449-462.

Farde L, Nordström AL, Wiesel FA, Pauli S, Halldin C, Sedvall G (1992). Positron emission tomographic analysis of central $D_{1}$ and $\mathrm{D}_{2}$ dopamine receptor occupancy in patients treated with classical neuroleptics and clozapine. Relation to extrapyramidal side effects. Arch Gen Psychiatry 49: 538-544.

Gadeberg P, Gundersen HJG, Tågeh $\varnothing j$ F (1999). How accurate are measurements on MRI? A study on multiple sclerosis using reliable 3D stereological methods. J Magn Reson Imaging 10: 72-79.

Gadeberg P, Gundersen HJG, Taageh $\varnothing j$ F, Jakobsen J (2002). MRI volume measurements of hypointense objects. A phantom study using stereological methods. J Neurosci Methods 114: 149-157.

Garcia-Fiñana M, Cruz-Orive LM, Mackay CE, Pakkenberg B, Roberts N (2003). Comparison of MR imaging against physical sectioning to estimate the volume of human cerebral compartments. Neuroimage 18: 505-516.

Gundersen HJG, Jensen EB (1987). The efficiency of systematic sampling in stereology and its prediction. J Microsc 147: 229-263.

Gundersen HJG, Jensen EBV, Kiêu K, Nielsen J (1999). The efficiency of systematic sampling in stereology-reconsidered. J Microsc 193: 199-211.

Gupta SK, Kunka RL, Metz A, Lloyd T, Rudolph G, Perel JM (1995). Effect of alosetron (a new $5-\mathrm{HT}_{3}$ receptor antagonist) on the pharmacokinetics of haloperidol in schizophrenic patients. J Clin Pharmacol 35: 202-207.

Gur RE, Maany V, Mozley PD, Swanson C, Bilker W, Gur RC (1998). Subcortical MRI volumes in neuroleptic-naive and treated patients with schizophrenia. Am J Psychiatry 155: 1711-1717.

Harrison PJ (1999). The neuropathology of schizophrenia: a critical review of the data and their interpretation. Brain 122: 593-624.

Harrison PJ, Lewis DA (2003). Neuropathology of schizophrenia. In: Hirsch S and Weinberger DR (eds). Schizophrenia, 2nd edn. Blackwell Science Ltd.: Oxford. pp 310-325.

Harrison PJ, Freemantle N, Geddes JR (2003). Meta-analysis of brain weight in schizophrenia. Schizophr Res 64: 25-34.

Haug H (1986). History of neuromorphometry. J Neurosci Methods 18: $1-17$.

Heckers S, Heinsen H, Geiger B, Beckmann H (1991). Hippocampal neuron number in schizophrenia. A stereological study. Arch Gen Psychiatry 48: 1002-1008.

Ho BC, Andreasen NC, Nopoulos P, Arndt S, Magnotta V, Flaum M (2003). Progressive structural brain abnormalities and their relationship to clinical outcome: a longitudinal magnetic resonance imaging study early in schizophrenia. Arch Gen Psychiatry 60: 585-594. 
Hochberg Y, Tamhane AC (1987). Multiple Comparison Procedures. Wiley: New York.

Hof PR, Haroutunian V, Friedrich Jr VL, Byne W, Buitron C, Perl DP et al (2003). Loss and altered spatial distribution of oligodendrocytes in the superior frontal gyrus in schizophrenia. Biol Psychiatry 53: 1075-1085.

Howard CV, Reed MG (1998). Unbiased Stereology. ThreeDimensional Measurement in Microscopy. Bios Scientific Publishers Ltd: Oxford.

Kapur S, Seeman P (2001). Does fast dissociation from the dopamine $\mathrm{D}_{2}$ receptor explain the action of atypical antipsychotics? A new hypothesis. Am J Psychiatry 158: 360-369.

Kapur S, Zipursky R, Jones C, Remington G, Houle S (2000). Relationship between dopamine $\mathrm{D}_{2}$ occupancy, clinical response, and side effects: a double-blind PET study of first-episode schizophrenia. Am J Psychiatry 157: 514-520.

Kapur S, Zipursky R, Roy P, Jones C, Remington G, Reed K et al (1997). The relationship between $D_{2}$ receptor occupancy and plasma levels on low dose oral haloperidol: a PET study. Psychopharmacology (Berl) 131: 148-152.

Kapur S, Zipursky RB, Remington G (1999). Clinical and theoretical implications of $5-\mathrm{HT}_{2}$ and $\mathrm{D}_{2}$ receptor occupancy of clozapine, risperidone, and olanzapine in schizophrenia. Am J Psychiatry 156: 286-293.

Kapur S, Zipursky RB, Remington G, Jones C, DaSilva J, WIlson AA et al (1998). 5- $\mathrm{HT}_{2}$ and $\mathrm{D}_{2}$ receptor occupancy of olanzapine in schizophrenia: a PET investigation. Am J Psychiatry 155: 921-928.

Kassahun K, Mattiuz E, Nyhart Jr E, Obermeyer B, Gillespie T, Murphy A et al (1997). Disposition and biotransformation of the antipsychotic agent olanzapine in humans. Drug Metab Dispos 25: 81-93.

Keefe RSE, Seidman LJ, Christensen BK, Hamer RM, Sharma T, Sitskoorn MM et al (2004). Comparative effect of atypical and conventional antipsychotic drugs on neurocognition in firstepisode psychosis: a randomized, double-blind trial of olanzapine versus low doses of haloperidol. Am J Psychiatry 161: 985-995.

Keshavan MS, Bagwell WW, Haas GL, Sweeney JA, Schooler NR, Pettegrew JW (1994). Changes in caudate volume with neuroleptic treatment. Lancet 344: 1434.

Lewis DA (2002). The human brain revisited: opportunities and challenges in postmortem studies of psychiatric disorders. Neuropsychopharmacology 26: 143-154.

Littell RC, Milliken GA, Stroup WW, Wolfinger RD (1996). SAS System for Mixed Models. SAS Institute Inc.: Cary, NC.

Løkkegaard A, Nyengaard JR, West MJ (2001). Stereological estimates of number and length of capillaries in subdivisions of the human hippocampal region. Hippocampus 11: 726-740.

Marner L, Pakkenberg B (2003). Total length of nerve fibers in prefrontal and global white matter of chronic schizophrenics. J Psychiatr Res 37: 539-547.

Mattiuz E, Franklin R, Gillespie T, Murphy A, Bernstein J, Chiu A et al (1997). Disposition and metabolism of olanzapine in mice, dogs, and rhesus monkeys. Drug Metab Dispos 25: 573-583.

McEvoy JP, Hogarty GE, Steingard S (1991). Optimal dose of neuroleptic in acute schizophrenia. A controlled study of the neuroleptic threshold and higher haloperidol dose. Arch Gen Psychiatry 48: 739-745.

McEvoy JP, Stiller RL, Farr R (1986). Plasma haloperidol levels drawn at neuroleptic threshold doses: a pilot study. J Clin Psychopharmacol 6: 133-138.

Mendis-Handagama SMLC, Ewing LL (1990). Sources of error in the estimation of Leydig cell numbers in control and atrophied mammalian testes. J Microsc 159: 73-82.

Neter J, Kutner MH, Nachtsheim CJ, Wasserman W (1996). Applied Linear Statistical Models, 4th edn. McGraw-Hill: Boston.
Niznikiewicz MA, Kubicki M, Shenton ME (2003). Recent structural and functional imaging findings in schizophrenia. Curr Opin Psychiatry 16: 123-147.

Nordström AL, Farde L, Wiesel FA, Forslund K, Pauli S, Halldin C et al (1993). Central D2-dopamine receptor occupancy in relation to antipsychotic drug effects: a double-blind PET study of schizophrenic patients. Biol Psychiatry 33: 227-235.

Nyberg S, Farde L, Halldin C, Dahl ML, Bertilsson L (1995). $\mathrm{D}_{2}$ dopamine receptor occupancy during low-dose treatment with haloperidol decanoate. Am J Psychiatry 152: 173-178.

Okubo Y, Saijo T, Oda K (2001). A review of MRI studies of progressive brain changes in schizophrenia. J Med Dent Sci 48: 61-67.

Olesen OV, Linnet K (1998). Determination of olanzapine in serum by high-performance liquid chromatography using ultraviolet detection considering the easy oxidability of the compound and the presence of other psychotropic drugs. J Chromatogr $B$ Biomed Sci Appl 714: 309-315.

Oosthuizen P, Emsley R, Jadri TH, Keyter N (2004). A randomized, controlled comparison of the efficacy and tolerability of low and high doses of haloperidol in the treatment of first-episode psychosis. Int J Neuropsychopharmacol 7: 125-131.

Pakkenberg B (1987). Post-mortem study of chronic schizophrenic brains. Br J Psychiatry 151: 744-752.

Pakkenberg B (1993). Total nerve cell number in neocortex in chronic schizophrenics and controls estimated using optical disectors. Biol Psychiatry 34: 768-772.

Pantelis C, Velakoulis D, McGorry PD, Wood SJ, Suckling J, Phillips LJ et al (2003). Neuroanatomical abnormalities before and after onset of psychosis: a cross-sectional and longitudinal MRI comparison. Lancet 361: 281-288.

Perry PJ, Lund BC, Sanger T, Beasley C (2001). Olanzapine plasma concentrations and clinical response: acute phase results of the North American Olanzapine Trial. J Clin Psychopharmacol 21: 14-20.

Perry PJ, Sanger T, Beasley C (1997). Olanzapine plasma concentrations and clinical response in acutely ill schizophrenic patients. J Clin Psychopharmacol 17: 472-477.

Pierri JN, Chaudry AS, Woo T-UW, Lewis DA (1999). Alterations in chandelier neuron axon terminals in the prefrontal cortex of schizophrenic subjects. Am J Psychiatry 156: 1709-1719.

Pierri JN, Volk CLE, Auh S, Sampson A, Lewis DA (2001). Decreased somal size of deep layer 3 pyramidal neurons in the prefrontal cortex of subjects with schizophrenia. Arch Gen Psychiatry 58: 466-473.

Rajkowska G, Halaris A, Selemon LD (2001). Reductions in neuronal and glial density characterize the dorsolateral prefrontal cortex in bipolar disorder. Biol Psychiatry 49: 741-752.

Rajkowska G, Selemon LD, Goldman-Rakic PS (1998). Neuronal and glial somal size in the prefrontal cortex: a postmortem morphometric study of schizophrenia and Huntington disease. Arch Gen Psychiatry 55: 215-224.

SAS Institute Inc. (1990). SAS/STAT User's Guide, Version 6, 4th edn, Vol 2, SAS Publishing: Cary, NC.

Scheepers FE, Gispen de Wied CC, Hulshoff Pol HE, van de Flier W, van der Linden JA, Kahn RS (2001). The effect of clozapine on caudate nucleus volume in schizophrenic patients previously treated with typical antipsychotics. Neuropsychopharmacology 24: 47-54.

Scherle W (1970). A simple method for volumetry of organs in quantitative stereology. Mikroskopie 26: 57-60.

Selemon LD, Kleinman JE, Herman MM, Goldman-Rakic PS (2002). Smaller frontal gray matter volume in postmortem schizophrenic brains. Am J Psychiatry 159: 1983-1991.

Selemon LD, Lidow MS, Goldman-Rakic PS (1999). Increased volume and glial density in primate prefrontal cortex associated with chronic antipsychotic drug exposure. Biol Psychiatry 46: 161-172. 
Shenton ME, Dickey CC, Frumin M, McCarley RW (2001). A review of MRI findings in schizophrenia. Schizophr Res 49: 1-52. Sporn AL, Greenstein DK, Gogtay N, Jeffries NO, Lenane M, Gochman P et al (2003). Progressive brain volume loss during adolescence in childhood-onset schizophrenia. Am J Psychiatry 160: 2181-2189.

Stark AK, Uylings HBM, Sanz-Arigita E, Pakkenberg B (2004). Glial cell loss in the anterior cingulate cortex, a subregion of the prefrontal cortex, in subjects with schizophrenia. Am J Psychiatry 161: 882-888.

Sweet RA, Bergen SE, Sun Z, Sampson AR, Pierri JN, Lewis DA (2004). Pyramidal cell size reduction in schizophrenia: evidence for involvement of auditory feedforward circuits. Biol Psychiatry 55: 1128-1137.

Sweet RA, Pierri JN, Auh S, Sampson AR, Lewis DA (2003). Reduced pyramidal cell somal volume in auditory association cortex of subjects with schizophrenia. Neuropsychopharmacology 28: 599-609.

Tauscher-Wisniewski S, Tauscher J, Logan J, Christensen BK, Mikulis DJ, Zipursky RB (2002). Caudate volume changes in first

episode psychosis parallel the effects of normal aging: a 5-year follow-up study. Schizophr Res 58: 185-188.

Thompson PM, Vidal C, Giedd JN, Gochman P, Blumenthal J, Nicolson $\mathrm{R}$ et al (2001). Mapping adolescent brain change reveals dynamic wave of accelerated gray matter loss in very early-onset schizophrenia. Proc Natl Acad Sci USA 98: $11650-11655$.

Thune JJ, Uylings HBM, Pakkenberg B (2001). No deficit in total number of neurons in the prefrontal cortex in schizophrenics. J Psychiatr Res 35: 15-21.

Weibel ER (1979). Stereological Methods. Volume 1: Practical Methods for Biological Morphometry. Academic Press: London.

Weis S, Haug H, Budka H (1996). Vascular changes in the cerebral cortex in HIV-1 infection: I. A morphometric investigation by light and electron microscopy. Clin Neuropathol 15: 361-366.

Young KA, Holcomb LA, Yazdani U, Hicks PB, German DC (2004). Elevated neuron number in the limbic thalamus in major depression. Am J Psychiatry 161: 1270-1277. 